\title{
Giant Fibrovascular Polyp of the Esophagus: A Novel Technical Approach
}

\author{
Juan José Trakál, ${ }^{1}$ Guillermo Jorge Sarquis, ${ }^{2}$ Juan Antonio Muñoz, ${ }^{2}$ Sergio Barril, ${ }^{1}$ \\ Esteban Trakál, ${ }^{1}$ Lucas Armando, ${ }^{3}$ and Rosa Carolina Gorordo Ipiña ${ }^{1}$ \\ ${ }^{1}$ Gastroenterology Service, Clínica Universitaria Reina Fabiola, Oncativo 1248 St., Córdoba 5000, Argentina \\ ${ }^{2}$ Thorax Surgery Service, Clínica Universitaria Reina Fabiola, Oncativo 1248 St., Córdoba 5000, Argentina \\ ${ }^{3}$ Histopathology Service, Clínica Universitaria Reina Fabiola, Oncativo 1248 St., Córdoba 5000, Argentina
}

Correspondence should be addressed to Juan José Trakál, juanjotrakal@hotmail.com

Received 19 April 2012; Accepted 23 May 2012

Academic Editors: A. J. Lembo and V. Lorenzo-Zúñiga

Copyright ( 92012 Juan José Trakál et al. This is an open access article distributed under the Creative Commons Attribution License, which permits unrestricted use, distribution, and reproduction in any medium, provided the original work is properly cited.

Fibrovascular polyps (FVPs) of the esophagus are rare, and their course is usually indolent until reaching enormous proportions. It is a dramatic entity owing to its tendency to cause bizarre complications. We describe a 49-year-old female patient with sudden dyspnoea that required digital maneuvers to clear the airway. After diagnosing, an FVP of the esophagus, a video-assisted endocavitary surgery was made. Histopathological examination revealed a fibrovascular polyp. Endoscopic controls after excision show no mass or symptoms recurrence.

\section{Introduction}

Fibrovascular polyps (FVPs) of the esophagus are benign, rare, intraluminal tumors [1-8] and represent less than $2 \%$ of esophageal tumors $[1-3,5-7]$. The most common complaints include dysphagia, foreign body sensation, weight loss, regurgitation of the mass, sudden death, and asphyxiation when the polyp regurgitates and occludes the larynx [1-9].

\section{Case Report}

A 49-year-old female patient described an episode of sudden dyspnoea that required digital maneuvers to clear the airway. She described that during the maneuver a smooth mass was detached from the pharynx and swallowed. Similar episodes were repeated in two occasions. During examination a progressive dysphagia to solids was noted. No history of loss weight, cough, or hematemesis was noted. She had no comorbidity of interest.

A CT scan was performed revealing a soft tissue mass in the esophagus, extending from the level of the cervical esophagus to the lower esophagus with no clear relation to the esophagus wall.
The upper endoscopy showed a sausage-shaped mass obstructing the esophageal lumen, arising from the upper esophageal sphincter and ending $13 \mathrm{~cm}$ below (Figure 1).

Technical Approach. Tracheal intubation previous to upper endoscopy was made; the mass measured $13 \times 1,5 \mathrm{~cm}$ and was sneared from his distal portion (Figure 2) and pulled into the mouth giving a clear image of the implantation base at the Killian's triangle. Once the distal portion of the tumor was fixed into the mouth and the base trapped by means of Kantrowitz forceps, the video-assisted endocavitary surgery started. The tumor was pulled by means of Magill forceps, and using laparoscopic surgical instrumentation and video assistance during the procedure the base of the tumor was electrocoagulated with the hook right above the Kantrowitz forceps (Figure 3) providing a clear control of possible hemorrhage (Figure 4). Immediate endoscopy was performed looking for possible complications of the procedure with negative results.

Twenty-four hours later the patient was able to eat soft meals and 48th hours after the procedure she was discharged.

Histopathological examination revealed a polypoid lesion covered by squamous epithelium with acanthosis 


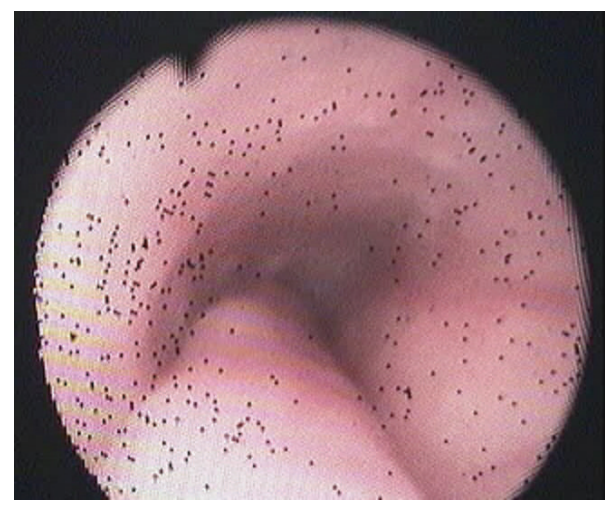

FIGURE 1: Sausage-shaped mass obstructing the esophageal lumen.

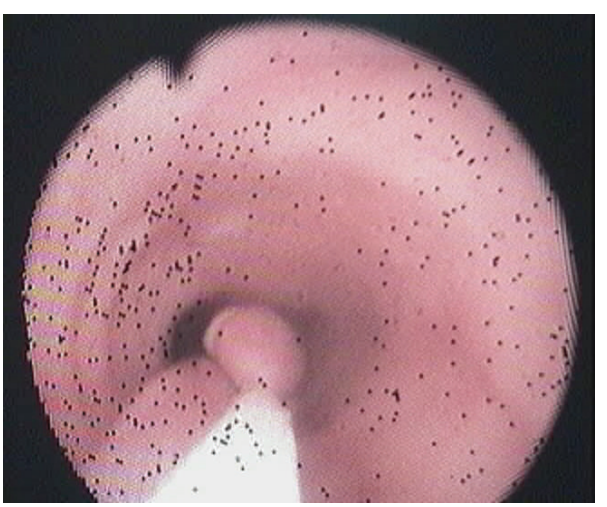

FIGURE 2: Sneared mass from his distal portion.

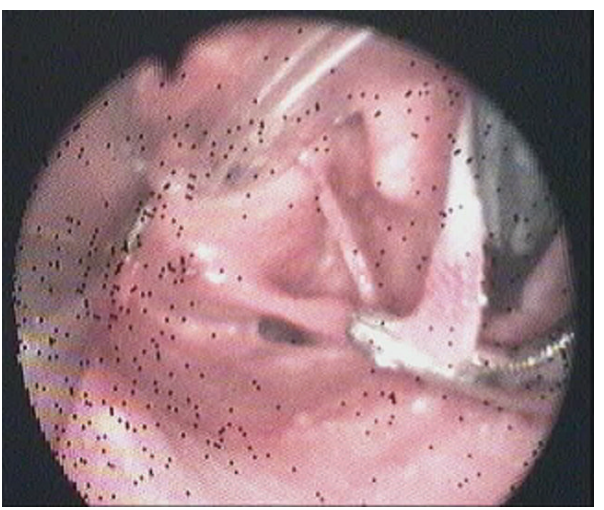

FiguRE 3: Base of the tumor electrocoagulated.

lining edematous stroma with areas of fibrosis. Blood vessels and abundant lymphoplasmacytic infiltrate (Figure 5), concluding fibrovascular polyp.

Endoscopic controls were made 4 months and 24 months after excision with no mass or symptoms recurrence.

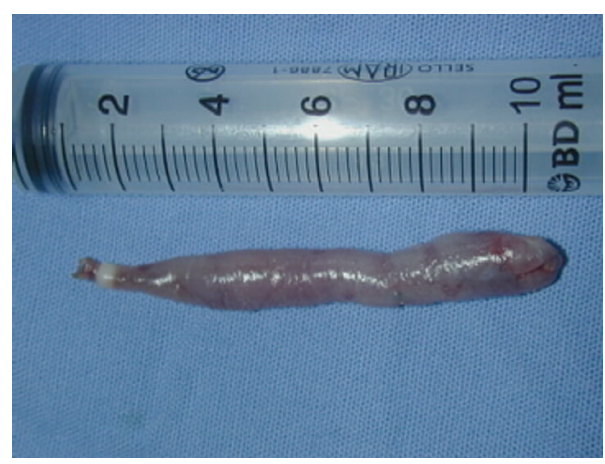

FIGURE 4: Sausage shaped mass after sugery.

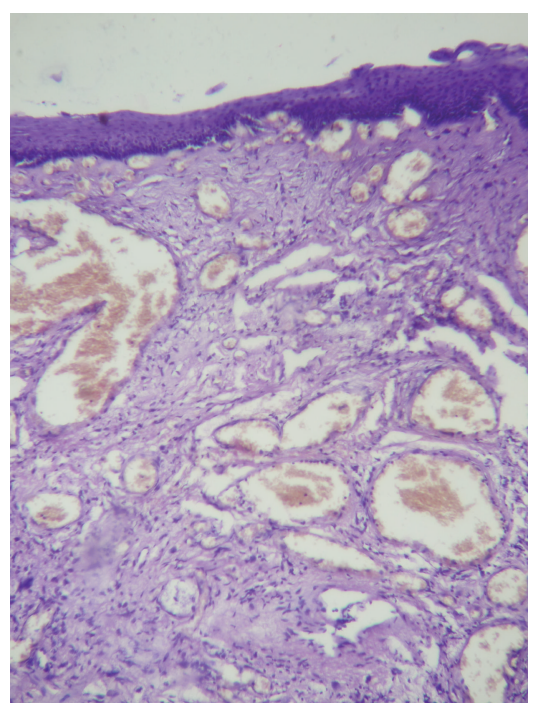

FIGURE 5: Polypoid lesion covered by squamous epithelium with acanthosis lining edematous stroma with areas of fibrosis. Blood vessels and abundant lymphoplasmacytic infiltrate.

\section{Discussion}

Despite its benign condition, it has a life threatening feared complication. This is an unusual tumor and different approaches have being proposed, including transverse 
cervical incision, transoral resection under direct visualization, endoscopic ligation and electrocoagulation of the pedicle (small size FVP), biapproach surgical technique (eoesophagostomy plus gastrostomy) and $\mathrm{CO}_{2}$ laser under laryngoscope [1-9].

The novel technical approach that we propose includes the safety and accuracy of transverse cervical incision, the simplicity of an endoscopic procedure, scarless, with early discharge and recovery.

It is important to consider that if FVP has become giant, it means we have got late to the patient, and this may be either because the patient shows no complaints, or because its symptoms have not been studied enough due to their nonspecificity.

\section{Conflict of Interests}

The authors have no conflict of interests to disclose.

\section{Acknowledgments}

Special thanks to Fernanda Cúneo and Fernando Bazan from the library of Universidad Católica de Córdoba for helping with the database and Daniela Trakál with the syntax.

\section{References}

[1] J. Wang, D. M. Han, X. Ni, L. J. Ma, J. Y. Ye, and Y. Xiao, "Fibrovascular polyp of the hypopharynx and esophagus," Chinese Medical Journal, vol. 124, no. 19, pp. 3182-3184, 2011.

[2] S. Ozdemir, O. Gorgulu, T. Selcuk, Y. Akbas, C. Sayar, and H. Sayar, "Giant fibrovascular polyp of the hypopharynx: per-oral endoscopic removal," Journal of Laryngology and Otology, vol. 125, no. 10, pp. 1087-1090, 2011.

[3] A. H. Goenka, S. Sharma, V. Ramachandran, T. K. Chattopadhyay, and R. Ray, "Giant fibrovascular polyp of the esophagus: report of a case," Surgery Today, vol. 41, no. 1, pp. 120-124, 2011.

[4] A. Goto, M. Suzuki, K. Iizuka et al., "Regurgitation of a mass into the mouth: a fibrovascular polyp of the esophagus," Endoscopy, vol. 42, supplement 2, pp. E248-E249, 2010.

[5] M. Peltz and A. S. Estrera, "Resection of a giant esophageal fibrovascular polyp," Annals of Thoracic Surgery, vol. 90, no. 3, pp. 1017-1019, 2010.

[6] R. Dutta, A. Kumar, K. K. Handa, and A. K. Dinda, "Large pedunculated fibrovascular polyp of oesophagus in a young woman," Interactive Cardiovascular and Thoracic Surgery, vol. 9, no. 2, pp. 352-353, 2009.

[7] M. M. Blacha, C. E. Sloots, I. P. Van Munster, and T. Wobbes, "Dysphagia caused by a fibrovascular polyp: a case report," Cases Journal, vol. 1, article 334, 2008.

[8] D. Chourmouzi and A. Drevelegas, "Giant fibrovascular polyp of the oesophagus: a case report and review of the literature," Journal of Medical Case Reports, vol. 2, article 337, 2008.

[9] S. Chauhan and P. Draganov, "Endoscopic removal of two giant fibrovascular polyps of the esophagus using the "two channel, two devices technique",' Gastrointestinal Endoscopy, vol. 73, no. 5, pp. 1036-1037, 2011. 


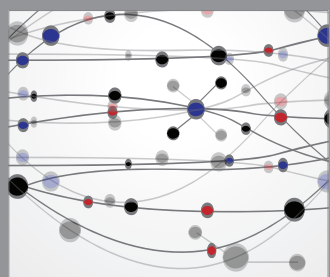

The Scientific World Journal
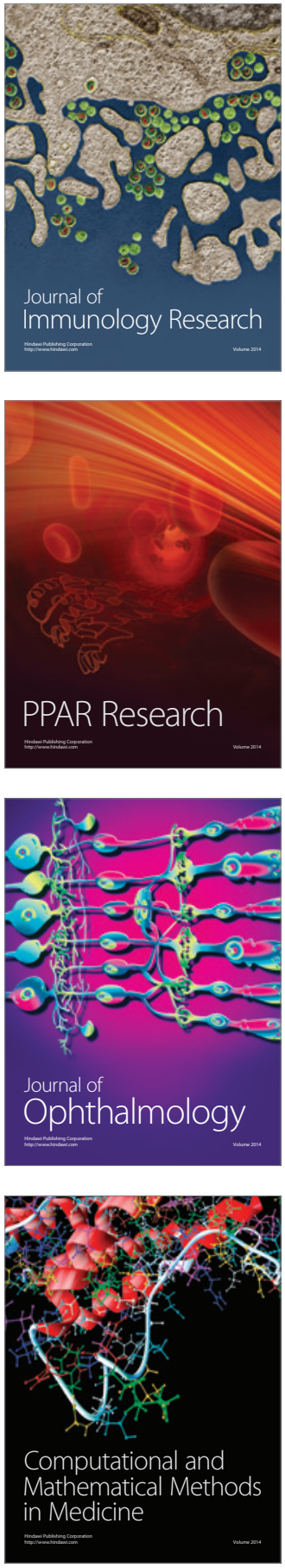

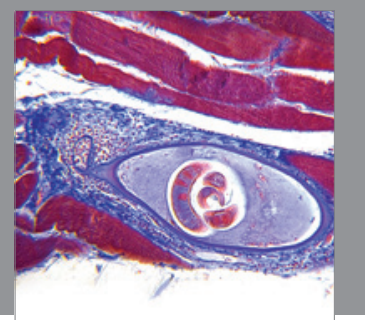

Gastroenterology

Research and Practice
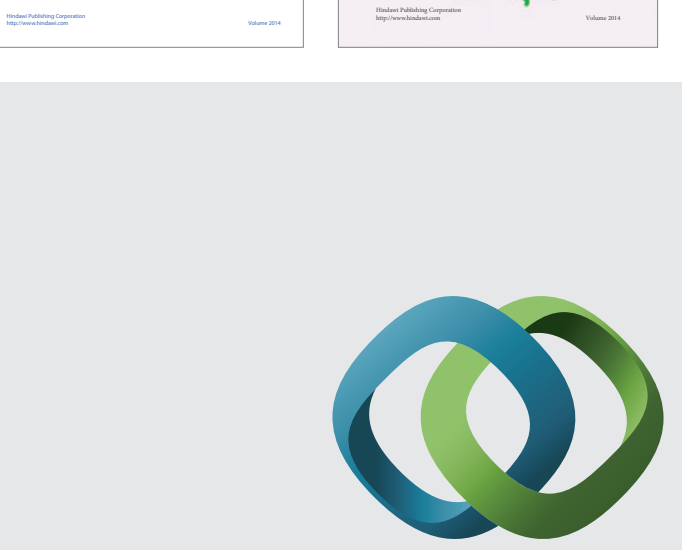

\section{Hindawi}

Submit your manuscripts at

http://www.hindawi.com
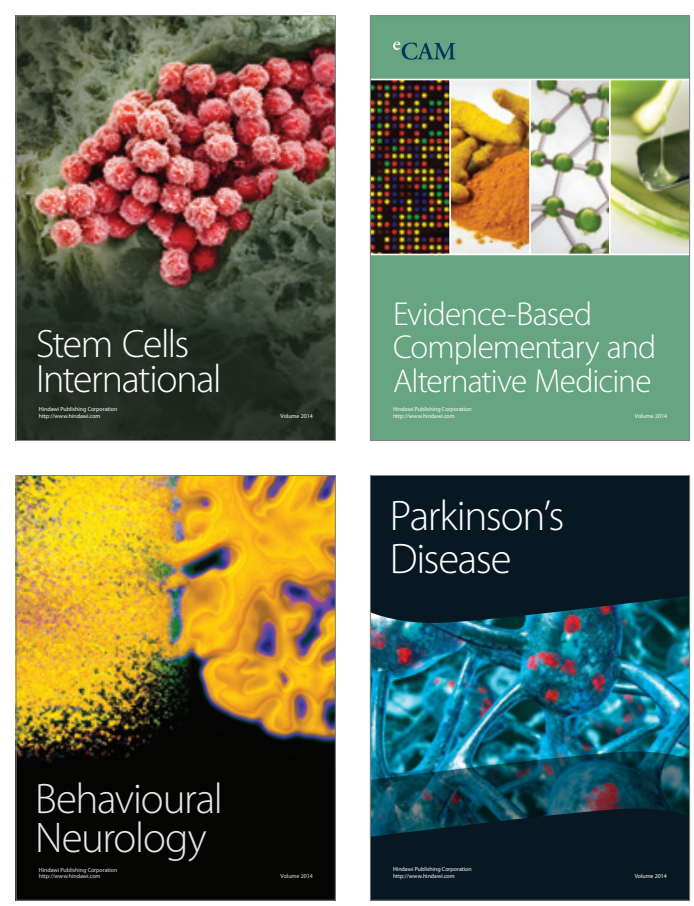

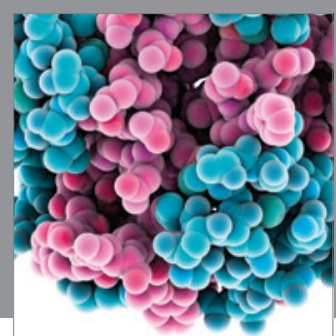

Journal of
Diabetes Research

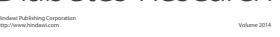

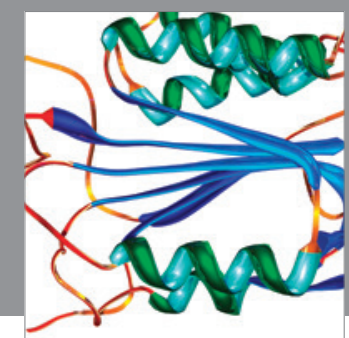

Disease Markers
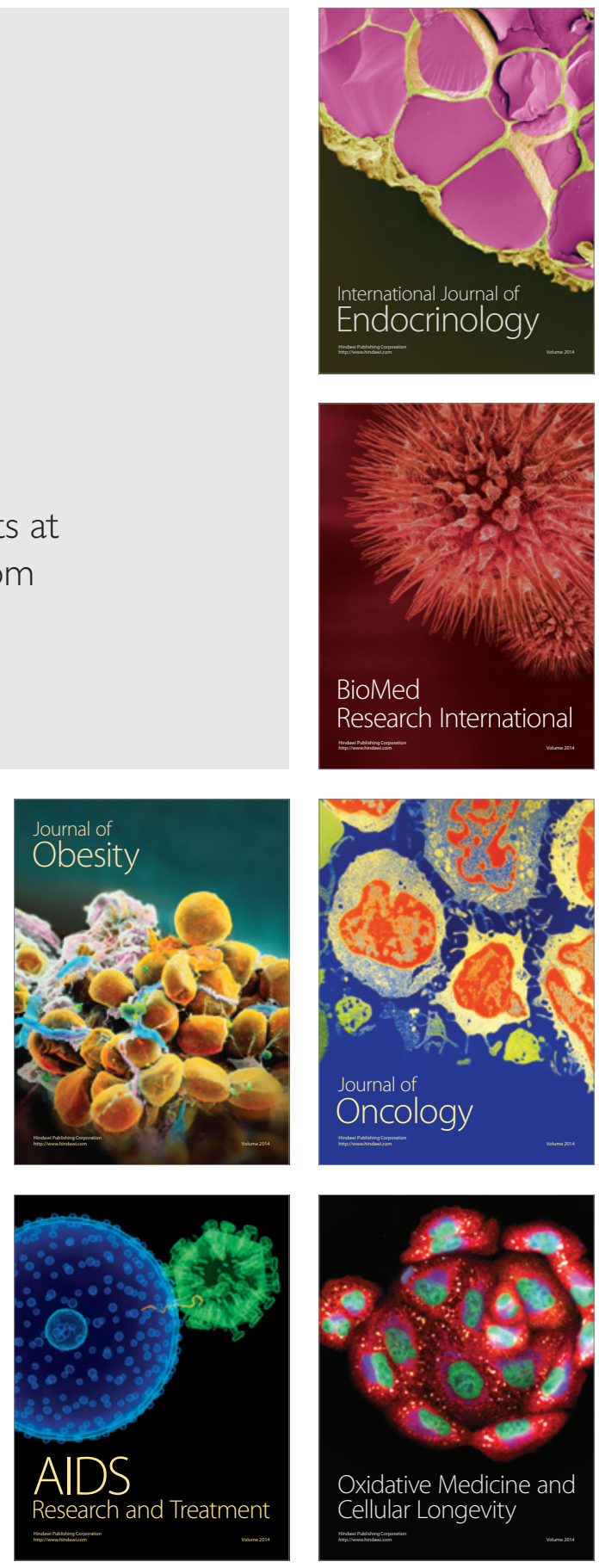